\title{
Optic pathway-hypothalamic glioma hemorrhage: a series of 9 patients and review of the literature
}

\author{
Kirsten van Baarsen, MD, PhD, ${ }^{1,2}$ Jonathan Roth, MD, ${ }^{1}$ Natalia Serova, MD, PhD, ${ }^{3}$ \\ Roger J. Packer, MD, ${ }^{4}$ Ben Shofty, MD, PhD, Ulrich-W. Thomale, MD, ${ }^{5}$ Giuseppe Cinalli, MD, ${ }^{6}$ \\ Helen Toledano, MBChB, ${ }^{7,8}$ Shalom Michowiz, MD, ${ }^{8,9}$ and Shlomi Constantini, MD, MSc ${ }^{1}$
}

\begin{abstract}
1Department of Pediatric Neurosurgery, International Israel Neurofibromatosis Center (IINFC), Dana Children's Hospital, Tel Aviv Medical Center, Tel Aviv University, Israel; ' 2 Department of Neurosurgery, Radboud University Medical Centre, Nijmegen, The Netherlands; ${ }^{3}$ Department of Neuro-ophthalmology, Burdenko Neurosurgical Institute, Moscow, Russia; ${ }^{4}$ Center for Neuroscience and Behavioral Medicine, Children's National Medical Center, Washington, DC; ${ }^{5}$ Department of Pediatric Neurosurgery, Charité Universitätsmedizin, Berlin, Germany; ${ }^{6}$ Department of Neurosurgery, Santobono-Pausilipon Children's Hospital, Naples, Italy; and Departments of ${ }^{7}$ Pediatric Oncology and ${ }^{~}$ Pediatric Neurosurgery, Schneider Children's Medical Center of Israel, Petach Tikva; and ${ }^{8}$ Sackler Faculty of Medicine, Tel Aviv University, Israel
\end{abstract}

OBJECTIVE Hemorrhage (also known as apoplexy) in optic pathway gliomas (OPGs) is rare. Because of the variable presentations and low incidence of OPG hemorrhages, little is known about their clinical course and the best treatment options. The aim of this work was to review risk factors, clinical course, and treatment strategies of optic glioma hemorrhages in the largest possible number of cases.

METHODS A total of 34 patients were analyzed. Nine new cases were collected, and 25 were identified in the literature. Data regarding demographics, radiological and histological features, treatment, and outcome were retrospectively reviewed.

RESULTS The majority of patients were younger than 20 years. Only 3 patients were known to have neurofibromatosis. The histopathological diagnosis was pilocytic astrocytoma in the majority of cases. Five patients had intraorbital hemorrhages, whereas 29 patients had intracranial hemorrhage; the majority of intracranial bleeds were treated surgically. Six patients, all with intracranial hemorrhage, died due to recurrent bleeding, hydrocephalus, or surgical complications. No clear risk factors could be identified.

CONCLUSIONS Intracerebral OPG hemorrhages have a fatal outcome in $20 \%$ of cases. Age, hormonal status, neurofibromatosis involvement, and histopathological diagnosis have been suggested as risk factors for hemorrhage, but this cannot be reliably established from the present series. The goals of surgery should be patient survival and prevention of further neurological and ophthalmological deterioration.

https://thejns.org/doi/abs/10.3171/2017.8.JNS163085

KEY WORDS optic glioma; hemorrhage; neurofibromatosis; apoplexy; blindness; hypothalamic glioma; third ventricle; low-grade glioma; astrocytoma; oncology

$\mathrm{O}$ PTIC pathway gliomas (OPGs; or hypothalamic gliomas) may involve the optic nerve, chiasm, hypothalamus, or optic tracts. These tumors constitute about $5 \%$ of all pediatric brain tumors ${ }^{20,41}$ but may also be newly diagnosed in adulthood. ${ }^{39}$ The majority of these tumors are low-grade pilocytic or pilomyxoid astrocytomas, but their clinical behavior and management are often vari- able and challenging. Treatment is individually tailored and consists of a combination of surgical and oncological therapy. ${ }^{37,38,40,41}$

Hemorrhages in OPGs are rare. Intratumoral hemorrhage is usually associated with malignant ("high-grade") brain tumors, either primary or metastases. Of the lowgrade tumors, pituitary adenomas are well known for their

ABBREVIATIONS EVD = external ventricular drain; NF1 = neurofibromatosis type 1; OPG = optic pathway glioma; VP = ventriculoperitoneal.

SUBMITTED April 24, 2017. ACCEPTED August 8, 2017.

INCLUDE WHEN CITING Published online February 9, 2018; DOI: 10.3171/2017.8.JNS163085. 
bleeding potential ${ }^{46}$ Surprisingly, in a series of primary brain tumors, the highest hemorrhage rate occurred in pilocytic astrocytomas. ${ }^{26}$ This higher bleeding incidence in astrocytomas was confirmed in other series..$^{25,36}$

Hemorrhage in pediatric brain tumors is uncommon, but it has been described. ${ }^{24}$ Some have argued that hemorrhage occurs more frequently in pediatric than adult tumors (5.3\% vs $2.3 \%)$, possibly because of larger tumor size and a higher frequency of malignant tumors in the pediatric population. ${ }^{46}$ Regarding hemorrhage in OPGs, only case reports have been described in the literature.

The presentation of OPG hemorrhages may vary greatly, depending on their location and size. They can be detected during surveillance MRI, or imaging may be performed because of acute or subacute symptoms. Because of their variable presentation and low incidence, little is known about the clinical course and best treatment options for OPG hemorrhage.

The aim of this study was to retrospectively collect patient data on spontaneous optic pathway and hypothalamic glioma hemorrhages in all age groups to recognize risk factors, clinical course, and possible treatment strategies.

\section{Methods}

Cases were collected from Dana Children's Hospital, Tel Aviv Medical Center (Tel Aviv, Israel); Burdenko Neurosurgical Institute (Moscow, Russia); Children's National Medical Center (Washington, DC); Charité Universitätsmedizin (Berlin, Germany); Santobono-Pausilipon Children's Hospital (Naples, Italy); and Schneider Children's Medical Center (Petach Tikva, Israel). The study was approved by the institutional review board of the Tel Aviv Medical Center.

For all cases, data on age, sex, neurofibromatosis type 1 (NF1) history, presenting symptoms, previous treatments, radiological features, histological diagnosis, treatment strategy, and outcome were retrospectively collected. Both symptomatic and asymptomatic hemorrhages were included. The bleeding could either be the presenting sign or occur during tumor treatment or follow-up. Patient and tumor characteristics as well as treatment regimens were evaluated with regard to the clinical outcome.

In addition to this retrospective case series, an exten- sive PubMed search confined to the English-language literature was performed, using the following key words: "optic glioma," "pilocytic astrocytoma," and "chiasm*" AND "apoplexy," "bleeding," and "h(a)emorrhage." All relevant articles were reviewed, and additional cases were identified from their references.

\section{Results}

We identified 9 cases of optic glioma hemorrhage from 6 neurosurgical centers. In addition, 27 cases were derived from the literature, either published as a case report or mentioned in a larger case series focusing on a different research question. Of these 27 cases, 2 were excluded because the causal relationship between the optic glioma and the bleeding (subdural in one case and intraorbital with central retinal vein occlusion in the other) was questionable. ${ }^{18,32}$ Therefore, 34 cases are included in this study (Table 1). Two cases of our own series are described here in more detail.

\section{Illustrative Cases \\ Case 1}

A 7-year-old boy was found to have poor vision in his left eye at a school screening. MRI revealed a large, vividly enhancing tumor in the chiasm/hypothalamic region, encasing the internal carotid, middle cerebral, and anterior cerebral arteries. Inversion recovery imaging identified 2 hypointense lesions that indicated asymptomatic hemorrhage. Spine MRI showed drop metastases in the cauda equina. The child did not have sufficient criteria for the diagnosis of NF1. The parents refused a biopsy, and the boy was treated with vincristine and carboplatin based on the suspicion of an OPG. Nine months later, the patient awoke with left-eye blindness. CT scanning showed bleeding inside the tumor. A conservative approach was taken, but 2 weeks later the patient's condition deteriorated, with severe headaches followed by unconsciousness. CT scanning showed massive bleeding inside the tumor, in the left frontal lobe, and within the ventricle, with hydrocephalus and a diffusely swollen brain (Fig. 1). A bifrontal decompressive craniectomy was performed, resulting in removal of blood clots, partial tumor removal, and

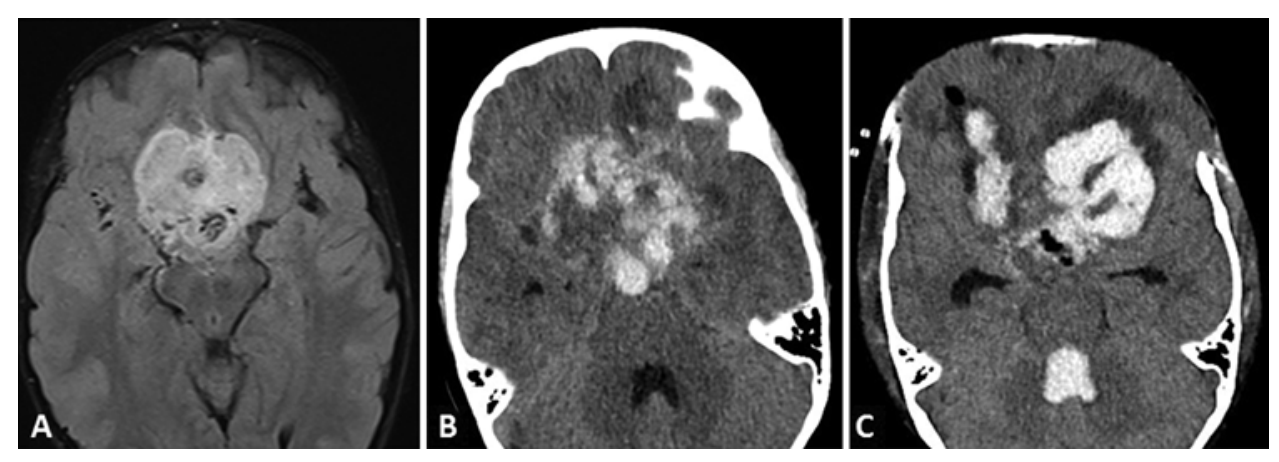

FIG. 1. Case 1. MR and CT images. A: Axial inversion recovery sequence showing 2 hypointensities within a large space-occupying lesion, indicating small (asymptomatic) intratumoral hemorrhages at regular follow-up. B: CT scan showing massive hemorrhage in the tumor region, leading to headaches followed by unconsciousness. C: CT scan showing intraventricular hemorrhage and status after bifrontal decompression. 

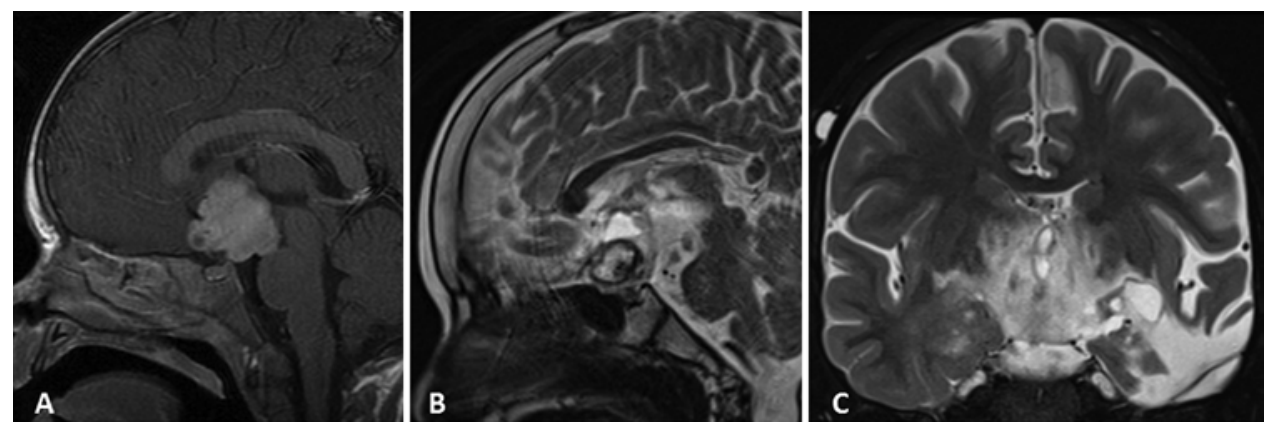

FIG. 2. Case 2. MR images. A: Sagittal T1-weighted image with gadolinium showing the tumor at regular follow-up. B: Sagittal T2-weighted image demonstrating ring-like hemorrhage artifact within the tumor. C: Coronal T2-weighted image showing edema in both amygdala regions, which was probably responsible for the fear attacks.

placement of bilateral external ventricular drains (EVDs). The histological diagnosis was pilocytic astrocytoma. The boy gradually improved. In the following months, the bone flap was replaced, and a ventriculoperitoneal (VP) shunt was inserted. At 8 months of follow-up, the patient had left-eye blindness, right-eye hemianopia, frontal lobe inhibition, and memory deficits, but he was able to attend a regular school. There are no endocrine deficits.

\section{Case 2}

A 3-year-old boy underwent neurological workup for developmental delay and café-au-lait spots. Ophthalmological examination revealed optic disc pallor, but the patient's vision seemed normal. MRI showed a $26-\mathrm{mm}$ enhancing chiasmatic lesion and hyperintense T2 changes in the cerebellar hemispheres. A diagnosis of NF1 with OPG was made. Because of tumor growth, the patient was treated with vincristine and carboplatin for several cycles. In addition, he underwent several surgical procedures for hydrocephalus and left basotemporal cyst formation, resulting in stable vision and neurological status. From 9 to 13 years of age, the patient had no evidence of tumor growth. During this time, the patient experienced severe intermittent headaches, which were treated with medicinal cannabis. At 13 years of age, he presented with dizziness, headaches, and severe panic attacks that he had never experienced before. MRI showed hemorrhage in the tumor as well as the bilateral rectus gyri, accompanied by edema in the upper brainstem and in both mesiotemporal regions (including the amygdala regions; Fig. 2). In retrospect, 2 small turbo inversion recovery magnitude hypointense lesions, suggestive of hemorrhages, were identified on the MRI performed 4 weeks earlier.

At presentation, there were no signs of increased intracranial pressure, and the patient's vision was unchanged; hence, he was treated conservatively with steroids and olanzapine (an antipsychotic agent). His headaches improved gradually, and his panic attacks disappeared. The clinical improvement was accompanied by gradual reduction in the edema and local pressure signs.

\section{Demographics}

The complete series (both our series and the cases identified in the literature) consisted of 19 females and 15 males (Table 1). Interestingly, 2 of the 19 females were pregnant at the time of optic glioma hemorrhage. The age histogram was skewed to the left, with far more patients younger than 20 years (median 13.5 years, interquartile range 15.3 years; Fig. 3 ). Only 3 patients (9\%) were diagnosed as having NF1. One had stigmata but did not fulfill the full diagnostic criteria. Neurofibromatosis status was unknown for 13 patients.

\section{Presenting Symptoms}

Five patients had a glioma of the optic nerve (Table 1) and presented with rapidly developing proptosis, pain, and decreased vision or even unilateral blindness at the time of hemorrhage. The other 29 patients had chiasm/hypothalamic gliomas. In those cases, hemorrhage mainly presented with headache, vomiting, and decreased consciousness due to acute hydrocephalus with elevated intracranial pressure. Depending on the location of the hemorrhage, these symptoms were sometimes accompanied by visual field and other neurological deficits. Endocrinological disturbances were mentioned in only 2 reports.

\section{Diagnostic Imaging Studies}

All patients underwent either CT or MRI. Eight of 34

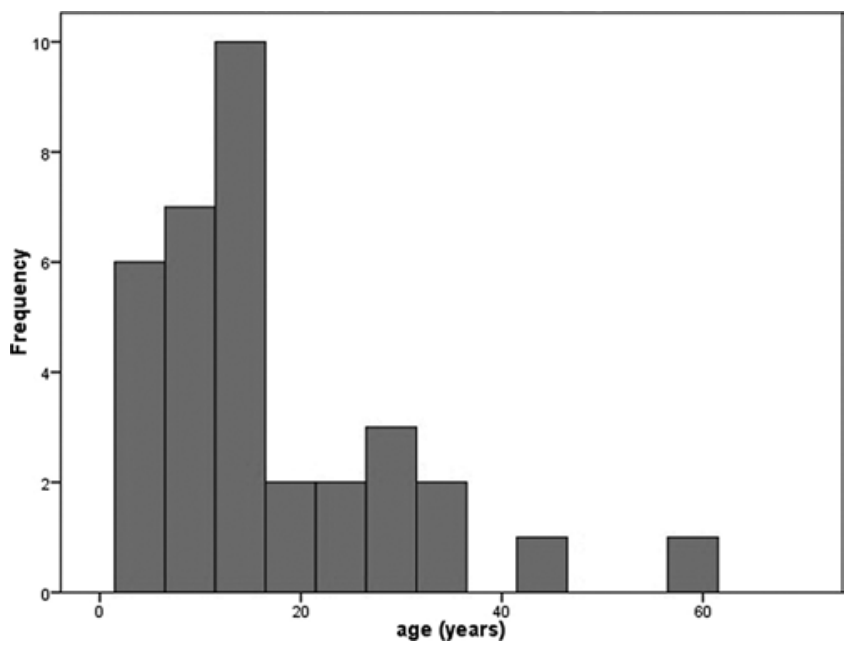

FIG. 3. Age histogram of all 34 patients with optic glioma hemorrhage. Note the skewed left deviation indicating a higher frequency of children and adolescents. 


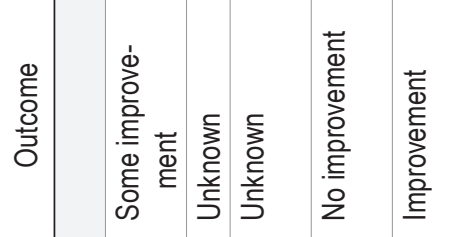

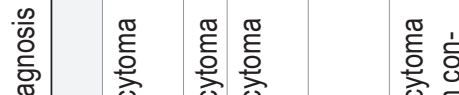

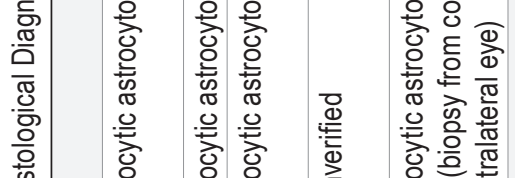

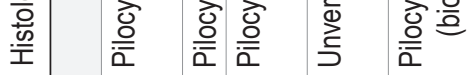

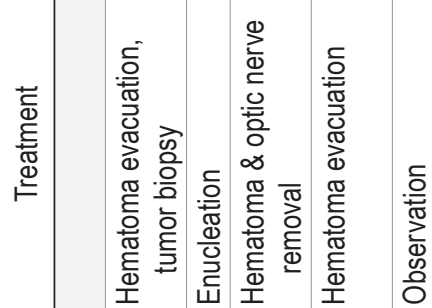

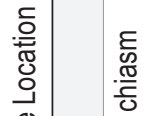

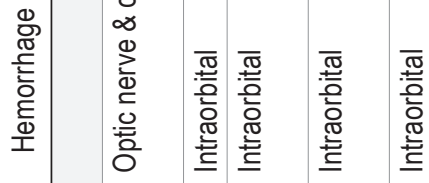

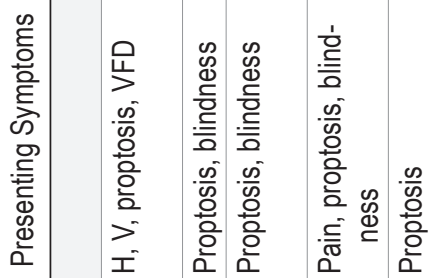

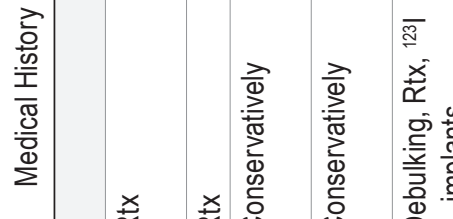

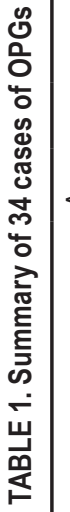

岂 욯

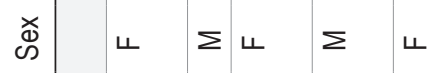

要总 은 $\forall \stackrel{\sim}{\circ}$

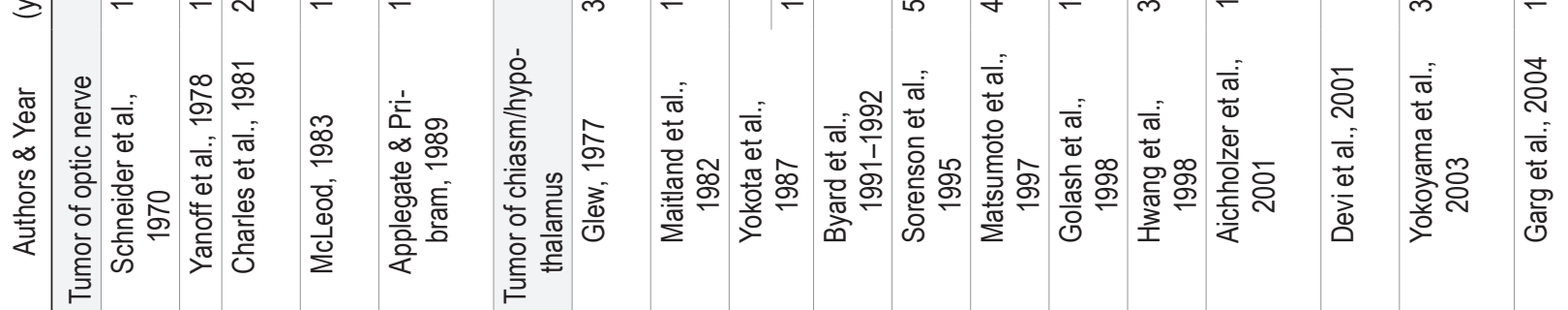

๙.

$\Sigma$ レ $\Sigma$ \

戾

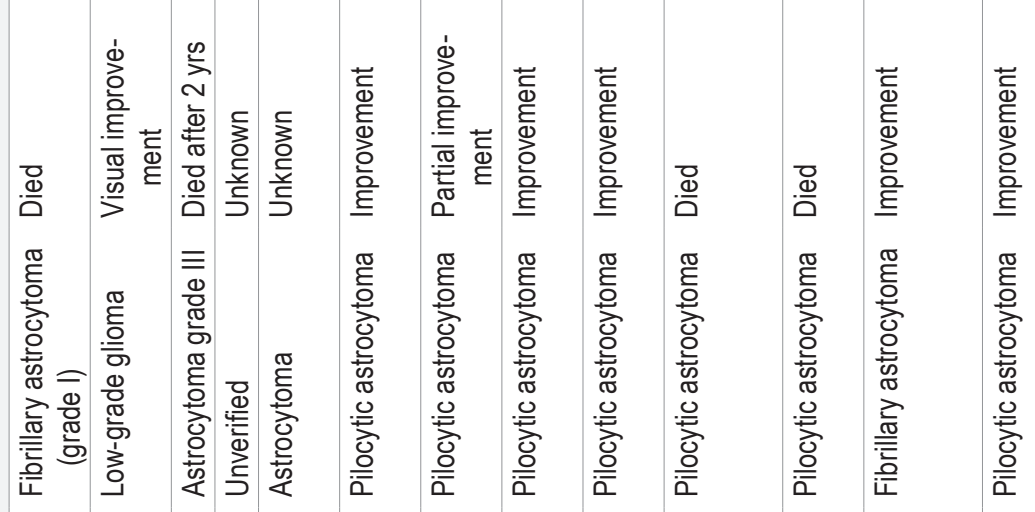

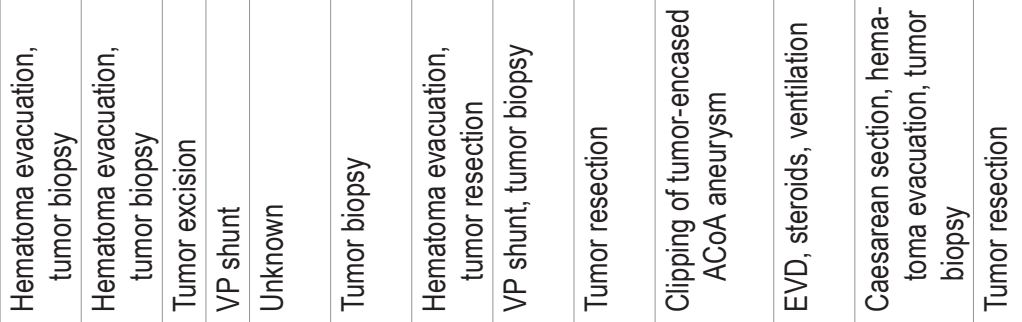

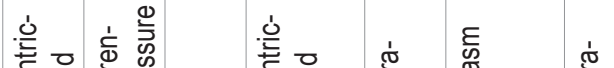

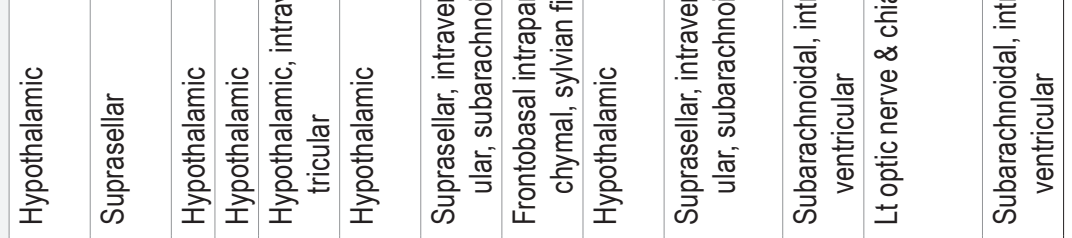

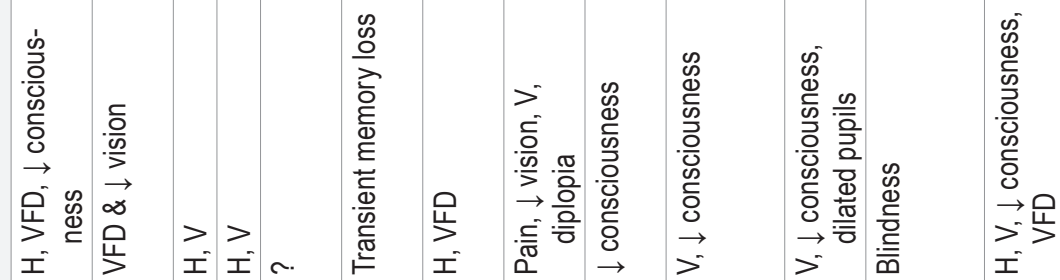

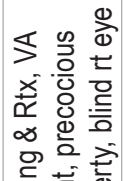

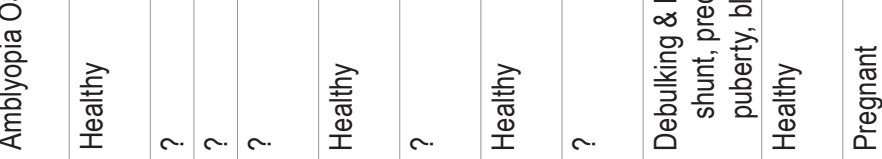

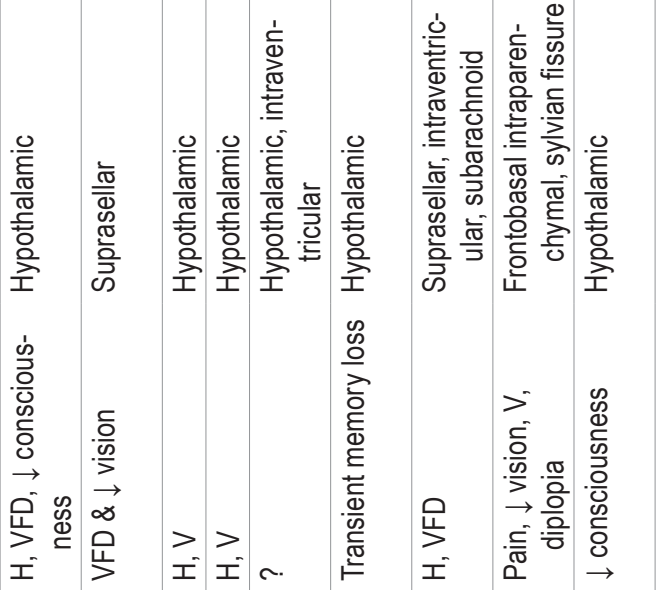




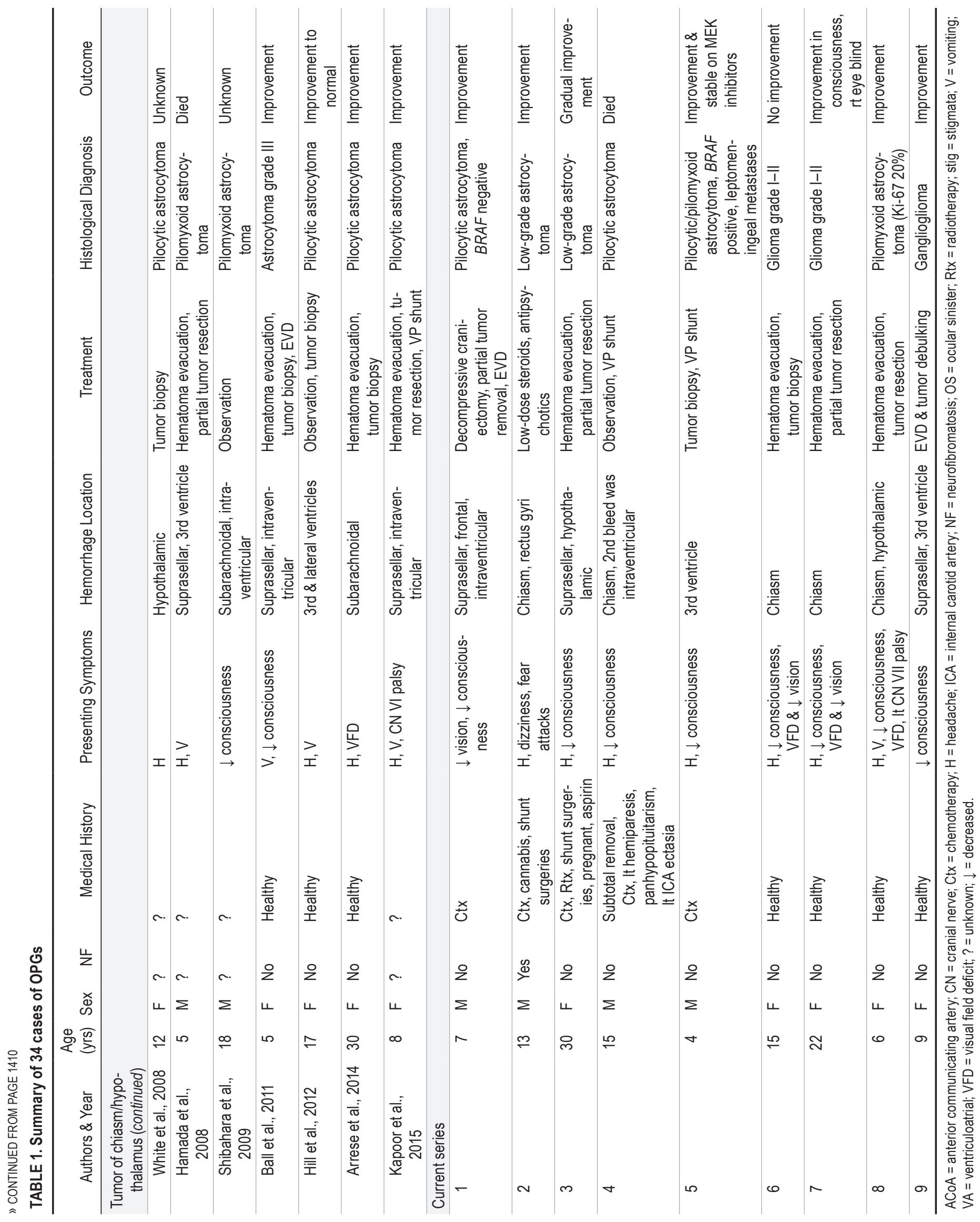


patients underwent further vascular imaging, mostly carotid angiography. In only one patient was a vascular abnormality identified. ${ }^{1}$

\section{Treatment}

The majority of patients with intracranial hemorrhage (26 of 29) were treated surgically, mostly by evacuation of the hematoma combined with partial tumor resection or tumor biopsy. Nine patients required either temporary or permanent CSF diversion. Only 2 patients were managed conservatively, one of whom improved and the other died. The treatment regimen was unknown in 1 patient.

\section{Pathology}

In this series, the pathological diagnosis was pilocytic astrocytoma (WHO grade I) in 17 patients (50\%), lowgrade glioma (not further specified) in 5 patients $(15 \%)$, pilomyxoid astrocytoma (WHO grade II) in 4 patients (12\%) (1 with a relatively high Ki-67 index of 20\%), fibrillary astrocytoma (WHO grade II) in 2 patients $(6 \%)$, grade III tumor in 2 patients $(6 \%)$, astrocytoma (not further specified) in 1 patient (3\%), ganglioglioma in 1 patient (3\%), and the histological diagnosis was unverified in 2 patients $(6 \%)$.

\section{Clinical Course}

Of all 34 patients, 20 experienced improvement in either visual function or neurological status, 2 experienced no improvement, and 6 patients died. The clinical course is unknown in the remaining 6 patients. All patients with intraorbital tumors survived.

Vision improved in 9 of 15 patients with visual field deficits. Of the 15 patients with decreased consciousness, 10 improved, whereas 5 did not. Of all 29 patients with intracerebral hemorrhage, 26 were treated surgically, of whom 18 (69\%) improved, 1 (4\%) remained stable, and 7 patients $(27 \%)$ deteriorated.

Of the 6 patients who died, 2 patients died of recurrent intracranial hemorrhage: one patient 2 weeks postoperatively and the other 4 months postoperatively after vincristine and cisplatin treatment. Two patients died in the immediate postoperative period due to complications of either the surgery or the hemorrhage. The fifth patient died 4 years postoperatively of acute cardiac failure. For the sixth patient, the cause of death is unknown.

\section{Discussion}

Hemorrhage in optic pathway or hypothalamic gliomas is a rare entity. Nevertheless, this study of 34 cases from an international collaboration and from the literature has given us some insight into the risk factors, clinical course, and treatment options.

\section{Risk Factors}

Several risk factors for optic glioma hemorrhage have been proposed. First, brain tumor hemorrhage seems to be associated with young age. ${ }^{6,36,46}$ However, this is probably confounded by the fact that the incidence of intratumoral hemorrhage is higher in low-grade astrocytomas, which are more frequent in children and adolescents. The mean age at presentation of optic glioma is 8.8 years..$^{10}$ These tumors typically occur during the 1st decade of life, and the incidence decreases with increasing age, corresponding to our "skewed deviation" in Fig. 3.

Despite a female preponderance for optic gliomas in general, ${ }^{8,35,45}$ there seems to be no sex difference in our series of optic glioma hemorrhage. However, it is interesting to note that 2 of 34 patients were pregnant, which is suggestive of hormonal influences on the development of optic glioma hemorrhage. Both women were in the 8th week of gestation, when estrogen levels are low, supporting Czyzyk and colleagues' hypothesis of estrogen depletion on optic glioma growth. ${ }^{8}$ Cerebral hemorrhage is indeed more common during pregnancy and puerperium due to hypertension, preeclampsia, vascular endothelial changes, and coagulopathy. Yet a direct hormonal association has not been reported. In one-third of all cases, intracranial hemorrhage during pregnancy is associated with an underlying vascular abnormality, such as an aneurysm or arteriovenous malformation..$^{22,31}$

Previous treatment regimens, such as chemotherapy or radiotherapy, have been suggested as predisposing factors for intratumoral hemorrhage, but this is not supported by the findings from our series. Only 5 of 34 patients had undergone treatment with chemotherapy prior to the hemorrhage and 5 with radiotherapy. Furthermore, many optic glioma patients worldwide are treated with combined chemo- and radiation therapy, yet optic glioma hemorrhage remains a rare phenomenon. In addition, 11 patients were completely healthy; in those cases, the hemorrhage was the presenting symptom of the optic glioma.

Medications such as aspirin (1 patient) may lead to a larger or more severe hemorrhage. This discussion is especially important for neurofibromatosis patients with both optic glioma and moyamoya syndrome, in whom antiplatelet drugs might be indicated to prevent ischemia but might, on the other hand, cause intratumoral hemorrhage. Cannabis, as the patient in case 2 was taking for headaches, may also be associated with intracranial hemorrhage, possibly due to changes in cerebral autoregulation and cerebral blood flow.42

Fifty percent of tumors were diagnosed as pilocytic, and $12 \%$ were diagnosed as pilomyxoid astrocytoma; one of the latter had a Ki-67 index of 20\%, indicating cell proliferation, which is associated with a poorer prognosis..$^{12}$ The differentiation between pilocytic and pilomyxoid in this series is somewhat arbitrary because pilomyxoid astrocytoma was not identified as a separate entity until 1999.44 In previous papers, a pilomyxoid astrocytoma would have been classified as a pilocytic astrocytoma. ${ }^{23}$

Compared with pilocytic astrocytomas, pilomyxoid astrocytomas have a more aggressive clinical course with shorter progression-free survival periods and a higher frequency of leptomeningeal spread. ${ }^{16}$ These tumors may be more vascularized with vessel proliferation and thinner vessel walls, possibly resulting in a greater tendency to bleed. ${ }^{16,21}$ Nevertheless, the incidence of the different histopathological entities in our series of optic glioma hemorrhages does not seem to be very different from that in optic glioma series without hemorrhage. ${ }^{11}$ Shibahara et al. ${ }^{36}$ suggested that optic glioma hemorrhage may be associated 
with NF1, as NF1 is also associated with other vascular disorders, such as moyamoya syndrome and aneurysms. However, the incidence of NF1 in this series is around $15 \%$, which matches the normal distribution in optic glioma patients ${ }^{48}$ and is not supportive of this hypothesis.

Three of our own patients had sustained a previous hemorrhage (1 symptomatic and 2 asymptomatic). Previous hemorrhage was not reported in any of the cases in the literature. In the majority of these cases, hemorrhage was the presenting sign, and, hence, previous imaging studies were not available. The incidence of previous (asymptomatic) hemorrhages cannot be reliably evaluated and may be underestimated. Clinical courses of patients with and without previous hemorrhages were comparable with regard to severity.

White et al. found evidence of hemorrhage at presentation (demonstrated by CT or MRI) in 11 (8\%) of 138 histologically proven pilocytic astrocytomas; only one of these hemorrhages was due to a tumor in the chiasm/hypothalamic area ${ }^{47}$ There was no difference in the incidence of hemorrhage between tumor locations. In many of the histological samples of the 138 pilocytic astrocytomas, there was evidence of previous hemorrhage. These hemorrhages were frequently associated with microscopic vascular changes, such as dense hyalinized vessels, foci of vascular endothelial hyperplasia, and ectatic veins. This suggests that asymptomatic hemorrhage is common in pilocytic astrocytomas. It does not necessarily lead to symptomatic hemorrhages or a more malignant course.

None of the patients from our own series had vascular studies. From the cases in the literature, carotid angiography was performed in 8 patients. $1,13,15,17,29,36,47,50$ In only one case, ${ }^{1}$ an aneurysm closely related to the tumor was demonstrated as the cause of the hemorrhage. In the other 7 cases, no vascular pathology was identified. Therefore, these data do not point to a vascular risk factor in patients with optic glioma hemorrhages.

\section{Presentation}

As our data demonstrate, the presenting symptoms in optic glioma hemorrhage may vary largely. Bleeding in intraorbital optic nerve tumors may lead to eye pain, acute decrease in vision, and proptosis (Table 1). Hemorrhage in the suprasellar region may resemble pituitary hemorrhage with headache, decreased vision, and hypopituitarism. ${ }^{4}$ Depending on the extent of the bleed, it may further lead to vomiting and decreased consciousness due to hydrocephalus and raised intracranial pressure. In addition, asymptomatic hemorrhages might be found on regular follow-up MRI (Fig. 1A). Hemorrhages that are asymptomatic at first may develop into large hematomas leading to emergency situations, as demonstrated in our case 1.

Remote hemorrhages, such as subdural hematoma or intraocular hematoma, have been described in relation to OPGs. However, a direct relation with intratumoral hemorrhage could not be demonstrated in these cases. ${ }^{18,32}$

\section{Imaging}

A CT scan is indicated in the acute setting to determine the location and extent of the hemorrhage. MRI is used to differentiate between tumor of the optic pathway and pitu- itary adenoma or vascular anomaly as the underlying pathology.$^{50}$ Depending on the age of the hemorrhage, it has a typical MRI appearance, with a hyper- or hypointense ring due to hemoglobin breakdown products around the lesion and susceptibility artifacts from iron deposition ${ }^{2}$ (Fig. 2).

Optic pathway hemorrhage is also known to occur from arteriovenous or cavernous malformations, ${ }^{7,33}$ which should always be considered in the differential diagnosis. Angiography should be selectively used to rule out vascular malformations, although cavernous hemangiomas of the optic pathways might not always be detected. ${ }^{7,17}$

\section{Clinical Course}

Our data suggest that hemorrhages from a glioma located in the optic nerve have a more benign course compared than hypothalamic hemorrhages. Bleeding in optic nerve gliomas is confined to the orbit, causing pain and visual disturbances but not intracerebral damage. These hemorrhages were not fatal in any of the cases, as opposed to the hypothalamic or intraventricular hemorrhages that were eventually fatal in 6 of 29 cases.

\section{Treatment Options}

Optic glioma hemorrhages are treated in different ways, ranging from close observation to ventricular drainage and craniotomy with extensive tumor resection.

Most intraorbital hemorrhages were treated surgically through a longitudinal incision in the optic nerve and evacuation of the hematoma. Vision improved in all patients. Surgical treatment was also advocated by Crocker et al., ${ }^{7}$ who demonstrated visual improvement in $87 \%$ of patients with a cavernous hemangioma of the optic chiasm. His findings are supported by those of Liu et al. ${ }^{27}$ This suggests that the hematoma splits the optic nerve fibers rather than disrupts them. Applegate and Pribram ${ }^{2}$ reported improvement in vision in a patient who was managed conservatively. Enucleation or resection of the optic nerve, as demonstrated by Charles et al., ${ }^{6}$ is rarely advocated at present, mainly for cosmetic reasons.

In this report, various surgical procedures were performed for the management of intracranial hematomas. Depending on the location of the hemorrhage, various approaches have been used, including transcallosal, frontotemporal, subfrontal, and endoscopic approaches. Ventricular drainage was performed in 9 cases. If the main cause of raised intracranial pressure is hydrocephalus, ventricular drainage seems to be sufficient. However, if either the tumor or the hemorrhage itself exhibits a significant mass effect, the patient may lose consciousness because of diencephalic compression. In such cases, surgical decompression by evacuation of the hematoma or debulking of the tumor may be indicated. This was the case in more than half of the patients.

Although surgery may be lifesaving (case 1), it might induce further complications and should be considered carefully. Sometimes conservative management is the best option (case 2). The main goal of surgery should be patient survival and prevention of further neurological deterioration. The advantage of histological diagnosis is of secondary importance, as it does not directly influence patient outcome in the short term. 


\section{Conclusions}

This paper presents a series of 9 newly diagnosed cases of optic pathway or hypothalamic glioma hemorrhages, in addition to 25 cases derived from the literature. We found that intraorbital hemorrhages have a fairly good prognosis in contrast to intracerebral (hypothalamic, intraventricular, or subarachnoid) hemorrhages, which had a fatal outcome in $21 \%$ of cases. Age, hormonal status, neurofibromatosis, and histopathological diagnosis have been suggested as risk factors for hemorrhage, but this cannot be reliably established from the present report. The decision for surgical or conservative treatment should be made on a case-by-case basis, keeping in mind that the goals of surgery should be patient survival and prevention of further neurological deterioration. In a minority of cases, visual loss is due to compression of the optic nerve, and evacuation of the hematoma may be advocated to restore vision.

\section{References}

1. Aichholzer M, Gruber A, Haberler C, Bertalanffy A, Slave I, Czech T: Intracranial hemorrhage from an aneurysm encased in a pilocytic astrocytoma-case report and review of the literature. Childs Nerv Syst 17:173-178, 2001

2. Applegate LJ, Pribram HF: Hematoma of optic nerve glioma-a cause for sudden proptosis. Magnetic resonance imaging findings. J Clin Neuroophthalmol 9:15-19, 1989

3. Arrese I, Sarabia R, Zamora T: Chiasmal haemorrhage secondary to glioma with unusual MRI appearance. Neurocirugia (Astur) 25:136-139, 2014

4. Ball BG, Wetmore C, Giannini C, Wetjen NM, Meyer FB: Opticochiasmatic apoplexy in a five-year-old. Pediatr Neurosurg 47:279-283, 2011

5. Byard RW, Bourne AJ, Hanieh A: Sudden and unexpected death due to hemorrhage from occult central nervous system lesions. A pediatric autopsy study. Pediatr Neurosurg 17:88-94, 1991-1992

6. Charles NC, Nelson L, Brookner AR, Lieberman N, Breinin GM: Pilocytic astrocytoma of the optic nerve with hemorrhage and extreme cystic degeneration. Am J Ophthalmol 92:691-695, 1981

7. Crocker M, DeSouza R, King A, Connor S, Thomas N: Cavernous hemangioma of the optic chiasm: a surgical review. Skull Base 18:201-212, 2008

8. Czyzyk E, Jóźwiak S, Roszkowski M, Schwartz RA: Optic pathway gliomas in children with and without neurofibromatosis 1. J Child Neurol 18:471-478, 2003

9. Devi BI, Shukla D, Bhat D, Santosh V: Hypothalamic tumour with haemorrhage. Childs Nerv Syst 17:567-569, 2001

10. Dutton JJ: Gliomas of the anterior visual pathway. Surv Ophthalmol 38:427-452, 1994

11. El Beltagy MA, Reda M, Enayet A, Zaghloul MS, Awad M, Zekri W, et al: Treatment and outcome in 65 children with optic pathway gliomas. World Neurosurg 89:525-534, 2016

12. Fisher BJ, Naumova E, Leighton CC, Naumov GN, Kerklviet N, Fortin D, et al: Ki-67: a prognostic factor for low-grade glioma? Int J Radiat Oncol Biol Phys 52:996-1001, 2002

13. Garg A, Chugh M, Gaikwad SB, Chandra SP, Gupta V, Mishra NK, et al: Juvenile pilocytic astrocytoma presenting with subarachnoid hemorrhage. Case report and review of the literature. J Neurosurg 100 (5 Suppl Pediatrics):525-529, 2004

14. Glew WB: Simulated pituitary apoplexy: report of an unusual case due to hemorrhage into hypothalamic astrocytoma. Ann Ophthalmol 9:139-142, 1977

15. Golash A, Thorne J, West CG: Low grade pilocytic astrocy- toma presenting as a spontaneous intracerebral haemorrhage in a child. Br J Neurosurg 12:59-62, 1998

16. Hamada H, Kurimoto M, Hayashi N, Nagai S, Kurosaki K, Nomoto K, et al: Pilomyxoid astrocytoma in a patient presenting with fatal hemorrhage. Case report. J Neurosurg Pediatr 1:244-246, 2008

17. Hill JD, Rhee MS, Edwards JR, Hagen MC, Fulkerson DH: Spontaneous intraventricular hemorrhage from low-grade optic glioma: case report and review of the literature. Childs Nerv Syst 28:327-330, 2012

18. Hovland KR, Ellis PP: Hemorrhagic glaucoma with optic nerve glioma. Arch Ophthalmol 75:806-809, 1966

19. Hwang SL, Huang TY, Chai CY, Howng SL: Hypothalamic juvenile pilocytic astrocytoma presenting with intracerebral hemorrhage. J Formos Med Assoc 97:784-787, 1998

20. Jahraus CD, Tarbell NJ: Optic pathway gliomas. Pediatr Blood Cancer 46:586-596, 2006

21. Kapoor A, Savardekar A, Tewari MK, Chatterjee D, Radotra BD: Spontaneous hemorrhages in pediatric supratentorial pilocytic astrocytomas. Malignant presentation of a benign entity. Childs Nerv Syst 31:1617-1620, 2015

22. Khan M, Wasay M: Haemorrhagic strokes in pregnancy and puerperium. Int J Stroke 8:265-272, 2013

23. Komotar RJ, Mocco J, Zacharia BE, Wilson DA, Kim PY, Canoll PD, et al: Astrocytoma with pilomyxoid features presenting in an adult. Neuropathology 26:89-93, 2006

24. Kumar A, Deopujari CE, Biyani N, Mhatre MV: Pediatric cerebellar pilocytic astrocytoma presenting with hemorrhage. Neurol India 58:972-974, 2010

25. Licata B, Turazzi S: Bleeding cerebral neoplasms with symptomatic hematoma. J Neurosurg Sci 47:201-210, 2003

26. Lieu AS, Hwang SL, Howng SL, Chai CY: Brain tumors with hemorrhage. J Formos Med Assoc 98:365-367, 1999

27. Liu JK, Lu Y, Raslan AM, Gultekin SH, Delashaw JB Jr: Cavernous malformations of the optic pathway and hypothalamus: analysis of 65 cases in the literature. Neurosurg Focus 29(3):E17, 2010

28. Maitland CG, Abiko S, Hoyt WF, Wilson CB, Okamura T: Chiasmal apoplexy. Report of four cases. J Neurosurg 56:118-122, 1982

29. Matsumoto K, Akagi K, Abekura M, Maeda Y, Kitagawa M, Ryujin H, et al: Hypothalamic pilocytic astrocytoma presenting with intratumoral and subarachnoid hemorrhage. Neurol Med Chir (Tokyo) 37:849-851, 1997

30. McLeod AR: Acute blindness in childhood optic glioma caused by hematoma. J Pediatr Ophthalmol Strabismus 20:31-33, 1983

31. Moatti Z, Gupta M, Yadava R, Thamban S: A review of stroke and pregnancy: incidence, management and prevention. Eur J Obstet Gynecol Reprod Biol 181:20-27, 2014

32. Mori K, Takeuchi J, Handa H: Subdural effusion and brain tumor: case report and survey of the literature. Surg Neurol 3:257-260, 1975

33. Newman H, Nevo M, Constantini S, Maimon S, Kesler A: Chiasmal cavernoma: a rare cause of acute visual loss improved by prompt surgery. Pediatr Neurosurg 44:414-417, 2008

34. Schneider RC, Kriss FC, Falls HF: Prechiasmal infarction associated with intrachiasmal and suprasellar tumors. J Neurosurg 32:197-208, 1970

35. Shapey J, Danesh-Meyer HV, Kaye AH: Diagnosis and management of optic nerve glioma. J Clin Neurosci 18:15851591,2011

36. Shibahara I, Kanamori M, Kumabe T, Endo H, Sonoda Y, Ogawa Y, et al: Hemorrhagic onset of pilocytic astrocytoma and pilomy xoid astrocytoma. Brain Tumor Pathol 26:1-5, 2009

37. Shofty B, Ben-Sira L, Freedman S, Yalon M, Dvir R, Weintraub M, et al: Visual outcome following chemotherapy for 
progressive optic pathway gliomas. Pediatr Blood Cancer 57:481-485, 2011

38. Shofty B, Ben-Sira L, Kesler A, Constantini S: Optic pathway gliomas. Adv Tech Stand Neurosurg 42:123-146, 2015

39. Shofty B, Constantini S, Bokstein F, Ram Z, Ben-Sira L, Freedman S, et al: Optic pathway gliomas in adults. Neurosurgery 74:273-280, 2014

40. Shofty B, Mauda-Havakuk M, Weizman L, Constantini S, Ben-Bashat D, Dvir R, et al: The effect of chemotherapy on optic pathway gliomas and their sub-components: a volumetric MR analysis study. Pediatr Blood Cancer 62:1353-1359, 2015

41. Sievert AJ, Fisher MJ: Pediatric low-grade gliomas. J Child Neurol 24:1397-1408, 2009

42. Singh NN, Pan Y, Muengtaweeponsa S, Geller TJ, CruzFlores S: Cannabis-related stroke: case series and review of literature. J Stroke Cerebrovasc Dis 21:555-560, 2012

43. Sorenson EJ, Silbert PL, Benarroch EE, Jack CR, Parisi JE: Transient amnestic syndrome after spontaneous haemorrhage into a hypothalamic pilocytic astrocytoma. J Neurol Neurosurg Psychiatry 58:761-763, 1995

44. Tihan T, Fisher PG, Kepner JL, Godfraind C, McComb RD, Goldthwaite PT, et al: Pediatric astrocytomas with monomorphous pilomyxoid features and a less favorable outcome. J Neuropathol Exp Neurol 58:1061-1068, 1999

45. Varan A, Batu A, Cila A, Soylemezoğlu F, Balcı S, Akalan N, et al: Optic glioma in children: a retrospective analysis of 101 cases. Am J Clin Oncol 36:287-292, 2013

46. Wakai S, Yamakawa K, Manaka S, Takakura K: Spontaneous intracranial hemorrhage caused by brain tumor: its incidence and clinical significance. Neurosurgery 10:437-444, 1982

47. White JB, Piepgras DG, Scheithauer BW, Parisi JE: Rate of spontaneous hemorrhage in histologically proven cases of pilocytic astrocytoma. J Neurosurg 108:223-226, 2008
48. Yanoff M, Davis R, Zimmerman L: Juvenile pilocytic astrocytoma ('glioma') of the optic nerve. Clinicopathological study of sixty-three cases, in Jacobiec FA (ed): Ocular and Adnexal Tumors. Birmingham: Aescluapius, 1978, pp 658707

49. Yokota A, Kajiwara H, Matsuoka S, Kohchi M, Matsukado Y: Subarachnoid hemorrhage from brain tumors in childhood. Childs Nerv Syst 3:65-69, 1987

50. Yokoyama S, Takayama K, Sueda M, Ishikawa Y, Hirano H: Optic nerve glioma manifesting as intratumoral hemorrhage in a pregnant woman-case report. Neurol Med Chir (Tokyo) 43:559-562, 2003

\section{Disclosures}

The authors report no conflict of interest concerning the materials or methods used in this study or the findings specified in this paper.

\section{Author Contributions}

Conception and design: Constantini, van Baarsen, Roth. Acquisition of data: Constantini, van Baarsen, Roth, Serova, Packer, Thomale, Cinalli, Toledano, Michowiz. Analysis and interpretation of data: Constantini, van Baarsen, Roth. Drafting the article: Constantini, van Baarsen, Roth. Critically revising the article: all authors. Reviewed submitted version of manuscript: all authors. Administrative/technical/material support: van Baarsen. Study supervision: Constantini, Roth.

\section{Correspondence}

Shlomi Constantini: Dana Children's Hospital, Tel Aviv, Israel. sconsts@netvision.net.il. 